\title{
Effective Renewable Source Integration using Unified Power Quality Conditioner with Power Quality Enhancement in Three Phase System
}

\author{
P. Suresh ${ }^{1, *}$, and T. Gowri Manohar ${ }^{2}$ \\ ${ }^{1}$ Department of EEE, SV College of Engineering, Tirupati, AP, India \\ ${ }^{2}$ Department of EEE, SV University, Tirupati, AP, India
}

\begin{abstract}
This paper proposes a modified control strategy for unified Power Quality conditioner to alleviate voltage and current abnormalities in three phase system. Renewable source integration and nonlinear loads depreciates Power Quality of the system. Active Power Filters play a paramount role in alleviating PQ disturbances. To deal with current imperfections and reactive power compensation, modified dq controller is proposed for shunt controller. ANFIS-dq control strategy is proposed for Series Controller to suppress voltage imperfections Photovoltaic unit is optimally connected at DC link of UPQC for supporting controlling action and to deliver real power Proposed optimal renewable source integrated UPQC performance is studied with traditional PI and ANFIS controller. MATLAB / SIMULINK platform is used for analyzing proposed system performance.
\end{abstract}

\section{Introduction}

Usage of nonlinear loads, power electronics controlled loads and inductive loads have major impacts in PQ hindrance [1-2]. In addition, growing concerns over global warming and to supply dynamic power demand, renewable source integration becomes most viable solution [3-4]. Renewable source integration and nonlinear loads causes harmonics in current and voltage, reactive power demand and voltage disturbances like sag/swell. Grid side fluctuations also hinder power quality [5]. Predominantly passive filters have been replaced with active filters to tackle voltage and current abnormalities more effectively [6].

Shunt APF's compensates current harmonics, reactive power requirement and disturbances in current. Series APF's tackles voltage disturbances like sag/swell and harmonics. UPQC has coalesced characteristics of both series and shunt APF's. UPQC combinely alleviates voltage and current abnormalities [7-10]. Series part of UPQC deals with voltage imperfections and shunt part deals with current imperfections [11]. In literature, DC link controller [12], pq [13], dq[14], I cosø [4] etc. control strategies were proposed for shunt shunt APF. Similarly, PWM controller [15], Instantaneous reactive power theory [16], Synchronous Reference frame theory [17] phase locked loop [18], and Power angle control[1,3,7] were proposed for series APF. In this paper, modified dq

*Corresponding author: suresh.penagaluru@gmail.com 
controller is proposed for Shunt Converter (SHC) and ANFIS-dq controller is proposed for Series Converter (SEC) of UPQC.

\section{Proposed System Description}

Photovoltaic unit is fed at DC link UPQC. UPQC comprises of SHC and SEC. Reference currents for SHC are generated using modified dq controller and reference voltages are generated using ANFIS-dq controller. Modified dq controller has ability to deal with current harmonics suppression under supply disturbances and unbalanced conditions. UPQC acts as power quality mitigating device and power conditioning device for PV integration. Integrated PV source at DC link delivers required power to UPQC for mitigating current and voltage imperfections [3]. PV unit works as DC link voltage stabilizer and delivers the part of real power to load. Several maximum power point tracking algorithms are available for tracking maximum solar energy [19]. Ease of less parameters and uncomplicated feedback makes $\mathrm{P} \& \mathrm{O}$ as most preferred algorithm.

To study the performance of proposed PV fed UPQC, controlled voltage source is considered. For producing desired supply voltage distortions six different sinusoidal signals are considered and clubbed together. In order to get required waveforms following changes have been made, Change in Amplitude, Change in Phase Sequence and Change in Angular Frequency.

\subsection{Shunt Control Strategy}

Place Fig. 1 shows the Modified DQ Control Strategy. In this control strategy, initially supply currents $\left(\mathrm{I}_{\mathrm{sa}}, \mathrm{I}_{\mathrm{sb}}, \mathrm{I}_{\mathrm{sc}}\right)$, supply voltages $\left(\mathrm{V}_{\mathrm{sa}}, \mathrm{V}_{\mathrm{sb}}, \mathrm{V}_{\mathrm{sc}}\right)$, load currents $\left(\mathrm{I}_{\mathrm{La}}, \mathrm{I}_{\mathrm{Lb}}, \mathrm{I}_{\mathrm{Lc}}\right)$ and DC link voltages $\mathrm{V}_{\mathrm{dc}}$ are sensed. Later load currents are converted from abc frame to dq frame using Eqn.(1)

$$
\left[\begin{array}{l}
i_{d} \\
i_{q} \\
i_{0}
\end{array}\right]=\frac{2}{3}\left[\begin{array}{ccc}
\cos \emptyset & -\sin \emptyset & \frac{1}{2} \\
\cos \left(\emptyset-\frac{2 \Pi}{3}\right) & -\sin \left(\emptyset-\frac{2 \Pi}{3}\right) & \frac{1}{2} \\
\cos \left(\varnothing+\frac{2 \Pi}{3}\right) & \sin \left(\varnothing-\frac{2 \Pi}{3}\right) & \frac{1}{2}
\end{array}\right]\left[\begin{array}{l}
i_{l a} \\
i_{l b} \\
i_{l c}
\end{array}\right]
$$

These $I_{d}$ and $i_{q}$ components are passed through filter to get constant Dc components. $I_{d d c}$ is combined with the loss component, which is generated from tuned dc link error signal to get reference current $i_{d r e f}$.The loss component and direct axis reference current are shown in Eqn. (2) and Eqn. (3)

$$
\begin{aligned}
& \mathrm{i}_{\mathrm{ln}}=\mathrm{i}_{\mathrm{l}(\mathrm{n}-1)}+\mathrm{k}_{\mathrm{pd}}\left(\mathrm{V}_{\mathrm{de}(\mathrm{n})}-\mathrm{V}_{\mathrm{de}(\mathrm{n}-1)}+\mathrm{k}_{\mathrm{id}} \mathrm{V}_{\mathrm{de}(\mathrm{n})}\right. \\
& \mathrm{i}_{\mathrm{d}}^{*}=\mathrm{i}_{\mathrm{l}}+\mathrm{i}_{\mathrm{ddc}}
\end{aligned}
$$

Similarly $i_{\text {qdc }}$ is combined with the tuned supply voltage error signal to get reference current $\mathrm{I}_{\text {qref }}$ as shown in Eqn. (4). These reference $\mathrm{i}_{\text {dref }}$ and $\mathrm{i}_{\text {qref }}$ currents are converted back to abc reference frame using inverse park transformation, which are final reference currents given by Eqn.(5)

$$
\begin{aligned}
& \mathrm{i}_{\mathrm{qrn}}=\mathrm{i}_{\mathrm{qr}(\mathrm{n}-1)}+\mathrm{k}_{\mathrm{pq}}\left(\mathrm{V}_{\mathrm{te}(\mathrm{n})}-\mathrm{V}_{\mathrm{te}(\mathrm{n}-1)}+\mathrm{k}_{\mathrm{id}} \mathrm{V}_{\mathrm{te}(\mathrm{n})}\right. \\
& \mathrm{i}_{\mathrm{q}}^{*}=\mathrm{i}_{\mathrm{qr}}+\mathrm{i}_{\mathrm{qdc}}
\end{aligned}
$$

Using PWM controller gating pulses are generated based on the difference between reference and actual source currents. Based on gating pulses SHAF injects the cur-rents at PCC to suppress the harmonics in current and compensates the reactive power demanded. 


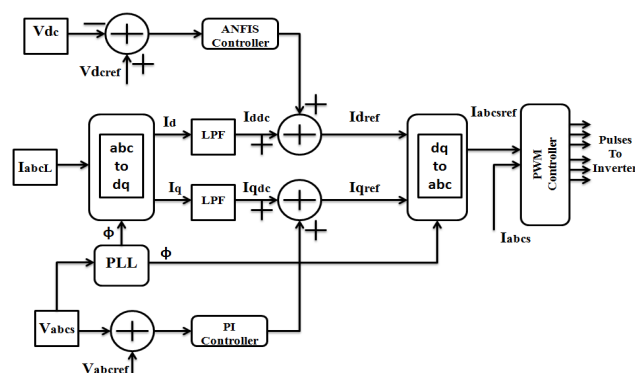

Fig 1. Shunt Controller

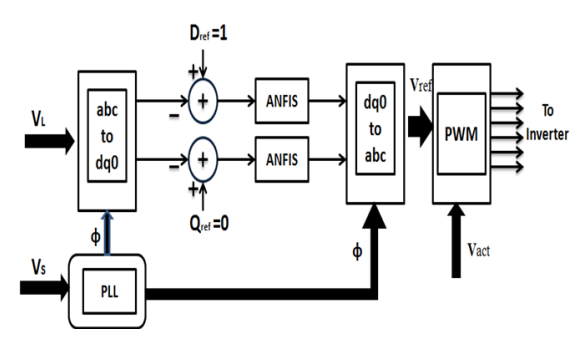

Fig 2. Series Controller

\subsection{Series Control Strategy}

Here, series controller purpose is to mitigate voltage sag, swell and interruption. It also compensates voltage harmonics. Proposed series voltage controller is as shown in Fig.2. Primarily, source voltages transformed into synchronous dq0 reference frame using,

$$
\mathrm{V}_{\mathrm{s} 1}^{\mathrm{dq} 0}=\mathrm{T}_{\mathrm{s}} * \mathrm{~V}_{\mathrm{s} 1}^{\mathrm{abc}}=\mathrm{V}_{\mathrm{s} 1 \mathrm{p}}+\mathrm{V}_{\mathrm{s} 1 \mathrm{n}}+\mathrm{V}_{\mathrm{s} 10}+\mathrm{V}_{\mathrm{s} 1 \mathrm{~h}}
$$

Where $\mathrm{V}_{\mathrm{slp}}, \mathrm{V}_{\mathrm{s} 1 \mathrm{n}}, \mathrm{V}_{\mathrm{s} 10}$, and $\mathrm{V}_{\mathrm{slh}}$ are positive, negative, zero sequence and harmonic component respectively.

Objective is to get sinusoidal voltage, so the dq0 reference frame of load voltage has,

$$
\begin{gathered}
\mathrm{V}_{\mathrm{L} 1}^{\mathrm{dq} 0}=\mathrm{T}_{\mathrm{s}} * \mathrm{~V}_{\mathrm{s} 1}^{\mathrm{abc}}=\left[\begin{array}{cc}
\mathrm{U}_{\mathrm{m}} \\
0 \\
0
\end{array}\right] \\
\text { Where } \mathrm{T}_{\mathrm{s}}=\left[\begin{array}{ccc}
\cos \emptyset & -\sin \emptyset & \frac{1}{2} \\
\cos \left(\varnothing-\frac{2 \Pi}{3}\right) & -\sin \left(\varnothing-\frac{2 \Pi}{3}\right) & \frac{1}{2} \\
\cos \left(\varnothing+\frac{2 \Pi}{3}\right) & \sin \left(\varnothing-\frac{2 \Pi}{3}\right) & \frac{1}{2}
\end{array}\right]
\end{gathered}
$$

The compensating dq0 reference frame voltage is given by,

$$
\mathrm{V}_{\mathrm{dq} 0}^{\mathrm{ref}}=\mathrm{V}_{\mathrm{s} 1}^{\mathrm{dq} 0}-\mathrm{V}_{\mathrm{L} 1}^{\mathrm{dq} 0}
$$

This compensating voltage is again transformed back to abc reference frame. Using SPWM the gate pulses are generated to compensate the Load voltage disturbance.

\subsection{ANFIS Controller}

ANFIS controller utilizes both Neural Network's adaptive learning features \& Fuzzy inference mechanism. Neuro-Fuzzy combination has proven its fine tuning of error signal ability in [5]. Here, ANFIS learning is a two direction learning process. Least Square Error learning is adopted for forward learning process. Back propagation learning is utilized in backward direction. Current ANFIS model, 3 fuzzy linguistic values are selected (Low, Medium and High) for single output and two inputs variables. 


\section{Simulation Results}

\subsection{Current \& Voltage profile}

Non linear loads connected to line inject harmonics. Fig. 3 shows modified dq controller based shunt converter injected currents to suppress source current harmonics. Shunt controller activated at $\mathrm{T}=0.1 \mathrm{sec}$. After $\mathrm{T}=0.1 \mathrm{sec}$, modified $\mathrm{dq}$ controller based shunt controller suppresses the nonlinearities in source current by injecting the opposing current under distorted supply voltage. Here, load current is served by both grid supply current and PV fed shunt injected current.

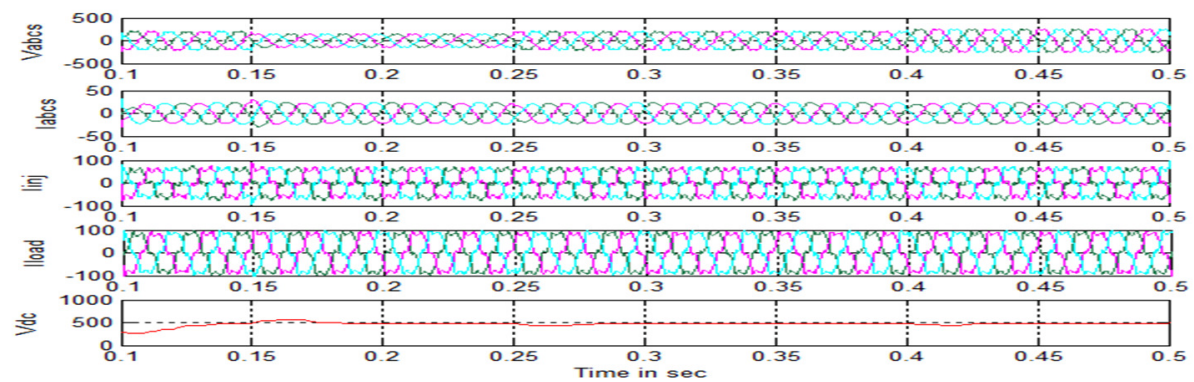

Fig. 3. Supply Voltage, Supply Current, Injected current, Load current and $V_{d c}$

Supply voltage has a sag of $25 \%$ between $0.15<\mathrm{t}<0.25$ and swell of $25 \%$ exists between $0.35<\mathrm{t}<0.5$. Series Converter (SEC) injects voltage for compensating sag and swell to deliver constant Load voltage. The same has been shown in Fig. 4. Proposed Series Controller is able to improve Load voltage profile.

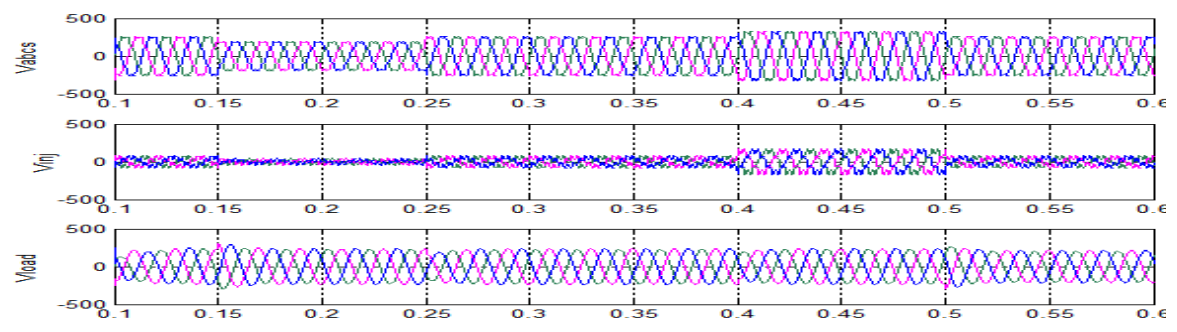

Fig. 4. Source Voltage, Injected Voltage and Load Voltage.

Fig. 5 shows the compensation of distorted and unbalanced supply voltage on load. Here, unbalanced sinusoidal voltages are created between $t=0.1 \mathrm{sec}$ to $\mathrm{t}=0.2 \mathrm{sec}$. Similarly distorted unbalanced voltages are created between $\mathrm{t}=0.2 \mathrm{sec}$ to $0.3 \mathrm{sec}$. SEC injects compensated voltages to suppress the abnormalities. Due to the injection of compensating voltage sinusoidal balanced voltages are delivered to Load.

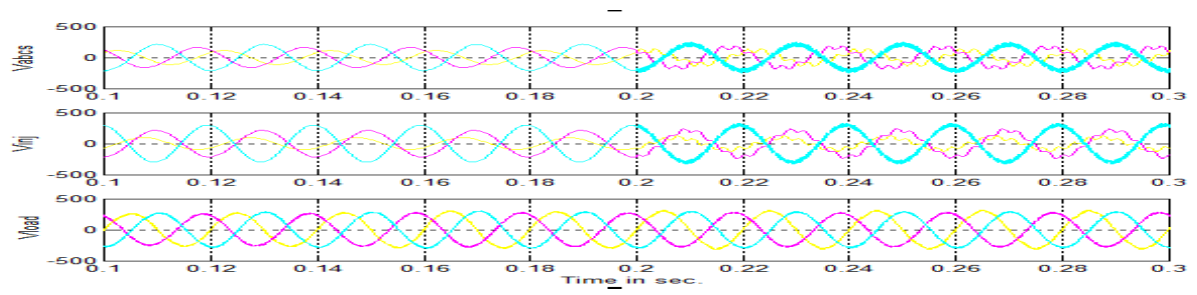

Fig 5. Unbalanced voltages on Line-1 


\subsection{Harmonics profile}

The harmonics reduction is analyzed under different conditions. Such as without UPQC, with PI-UPQC and ANFIS-UPQC.

Case1: \% THD of supply current without UPQC is presented in Fig.6 (a). Supply current $\%$ THD is more because of nonlinear loads.

Case2: UPQC is integrated at $\mathrm{T}=0.1 \mathrm{sec}$, post $\mathrm{T}=0.1 \mathrm{sec}, \%$ THD of supply current with PI controlled UPQC is shown in Fig. 6(a). Reduced \%THD of supply current with PI controller is $7.77 \%$. For further improvement, ANFIS technique is utilized in replacement of PI controller. \% THD of supply current with ANFIS controller is shown in Fig.6(a). Reduced \% THD of supply current with ANFIS is $4.31 \%$. Reduced \%THD of load-1 voltage with ANFIS controller is $2.03 \%$ and is shown in Fig. 6(b).

Table 1 and Table 2 presents specifications of proposed system and its performance comparison. From Table 2, ANFIS based shunt controller obtains \%THD within the IEEE standards. Also, ANFIS based series controller obtains \%THD of voltage with in specified standards.
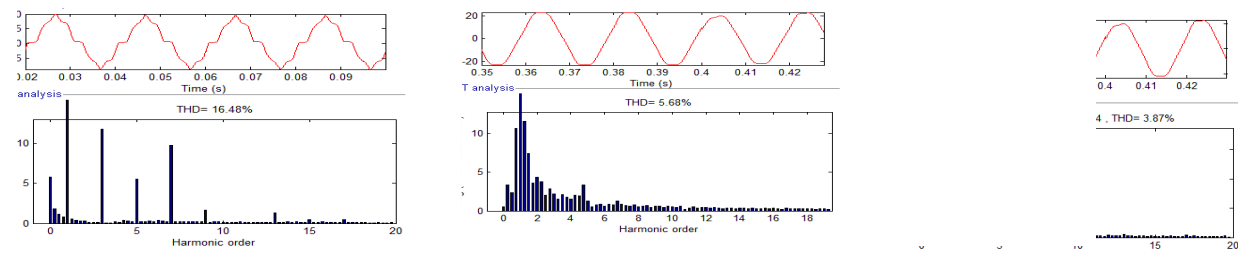

(a) Current \% THD without Controller, with PI Controller and with ANFIS Controller
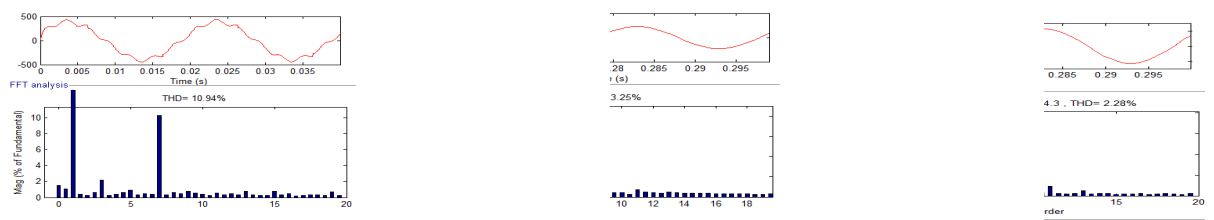

(b) Current \% THD without Controller, with PI Controller and with ANFIS Controller

Fig. 6. Current \& Voltage $\%$ THD with and without UPQC

Table 1. Proposed System Specifications

\begin{tabular}{|c|l|l|}
\hline $\begin{array}{c}\text { S. } \\
\text { No }\end{array}$ & Parameters & \multicolumn{1}{c|}{ Ratings } \\
\hline 1 & $\begin{array}{l}\text { Source } \\
\text { voltage }\end{array}$ & $\begin{array}{l}\text { 3-phase, } 230 \\
\text { V, } 50 \mathrm{~Hz}\end{array}$ \\
\hline 2 & Load & $\begin{array}{l}\mathrm{R}_{\mathrm{l}}=10 \Omega, \\
\mathrm{L}_{\mathrm{l}}=30 \mathrm{mH}\end{array}$ \\
\hline 4 & DC link & $\mathrm{V}_{\mathrm{dc}}=500 \mathrm{~V}$ \\
\hline 5 & Solar Cell & $35 \mathrm{~V}, 7.5 \mathrm{~A}$ \\
\hline
\end{tabular}

Table 2. Comparison of Power Factor, \% THD Source current and Load voltage

\begin{tabular}{|c|c|c|c|}
\hline Parameters & $\begin{array}{c}\text { Without } \\
\text { UPQC }\end{array}$ & $\begin{array}{c}\text { With PI } \\
\text {-UPQC }\end{array}$ & $\begin{array}{c}\text { With ANFIS- } \\
\text { UPQC }\end{array}$ \\
\hline P F & 0.58 & 0.91 & 0.91 \\
\hline \multicolumn{4}{|c|}{$\%$ THD } \\
\hline $\begin{array}{c}\text { Source } \\
\text { current }\left(\mathrm{I}_{\mathrm{a}}\right)\end{array}$ & 16.48 & 5.68 & 3.87 \\
\hline $\begin{array}{c}\text { Load } \\
\text { Voltage }\left(\mathrm{V}_{\text {la }}\right)\end{array}$ & 10.94 & 2.58 & 2.26 \\
\hline
\end{tabular}

\section{Conclusion}

In this paper modified dq control strategy is proposed for UPQC. Proposed method effectively compensates nonlinearities in load current and distortion in load voltages. Modified dq controller suppresses disturbances in current under supply voltage distortions. 
ANFIS controller gives better performance in current and voltage harmonics alleviation compared to traditional PI controller. Proposed controller achieves the following objectives

- $\quad$ ANFIS based modified dq controller proposed for SHC achieves \%THD of source current with IEEE standards.

- $\quad$ ANFIS-dq controller proposed for SEC achieves \%THD of voltage with in IEEE limits.

- Voltage imperfection like sag/swell compensated.

- Modified dq controller effectively suppresses nonlinearities under supply voltage distortion.

- $\quad$ PV unit delivers real power and supports UPQC controlling strategy.

\section{References}

1. M Singh, V Khadkikar, A Chandra, RK Varma. IEEE Trans. on power deliv. 26(1) 307-15, (2011)

2. S Mikkili, AK Panda, Int J Electr Power Energy Syst. 43(1), 1114-26, (2012)

3. NG Hingorani, L Gyugyi, M El-Hawary Understanding FACTS: concepts and technology of flexible AC transmission systems. (New York, IEEE press, 2000)

4. L Gyugyi, KK Sen, CD Schauder. IEEE Trans. on Power Deliv., 14(3), 1115-23, (1999)

5. SS Patnaik, K Panda, Int J Electr Power Energy Syst. 1(52) 185-97, (2013),.

6. AM Saeed, SH Aleem, AM Ibrahim, ME Balci, EE El-Zahab Journal of advanced research. 7(1) 95-103, (2016)

7. M Ramasamy, S Thangavel, Int J Electr Power Energy Syst. 36(1) 51-9, (2012)

8. Kasa S, Ramasamy S. Int. J. Renew. Energy,. 6(3) 825-32, (2016)

9. N Patnaik, AK Panda. Int J Electr Power Energy Syst.. 74 212-21, (2016)

10. K Palanisamy, DP Kothari, MK Mishra, S Meikandashivam, IJ Raglend Int J Electr Power Energy Syst. 48 131-8, (2013)

11. AR Reisi, MH Moradi, H Showkati Solar Energy. 88 154-62, (2013)

12. S Kasa, P Ramanathan,S Ramasamy, DP Kothari Int J Electr Power Energy Syst. 82 150-60, (2016)

13. B Fardanesh, B Shperling, E Uzunovic, S Zelingher In Power Engineering Society Summer Meeting, IEEE. 2 1020-1025, (2000)

14. PC Babu, SS Dash, C Subramani, SH Kiran. J Elect Engg \& Tech. 10(1) 379-87, (2015)

15. HR Mohammadi, AY Varjani, H Mokhtari IEEE Trans. on Power Deliv. 24(3) 167986, (2009).

16. BS Mohammed, R Ibrahim, N Perumal, KR Rao Journal of Electrical Engineering \& Technology. 10(1) 8-17, (2015)

17. SW Mohod, MV ,IEEE systems journal. 4(3) 346-52, (2010)

18. MI Montero, ER Cadaval, FB Gonzalez IEEE Trans. on Power Elec. 22(1) 229-36, (2007)

19. N Zaveri, A Chudasama Int J Electr Power Energy Syst. 42(1) 661-71, (2012) 